\title{
Genetic analysis in cystic fibrosis using the amplification refractory mutation system (ARMS): the J3.11 MspI polymorphism
}

Clive R Newton, Claire Summers, Lesley E Heptinstall, Jennifer R Lynch, Rachel S Finniear, Donald Ogilvie, John C Smith, Alexander F Markham

\begin{abstract}
A new method of genetic analysis has been devised. The method, amplification refractory mutation system (ARMS), has been used to genotype the J3.11 MspI restriction fragment length polymorphism (RFLP) closely linked to cystic fibrosis $(C F)$. The DNA sequence for both alleles of this dimorphism has been used to design ARMS primers. These allow genotyping of DNA isolated from blood, Guthrie cards, and buccal cells.
\end{abstract}

The ARMS method allows discrimination of alleles differing by a single base pair using a polymerase chain reaction (PCR) with selectively modified primers. ${ }^{1}$ ARMS does not require DNA of the quantity and quality necessary for conventional filter hybridisation analysis of RFLPs and less than $100 \mathrm{ng}$ of DNA is required.

Purified DNA from peripheral leucocytes and chorionic villus biopsy has been genotyped using ARMS. ${ }^{2}$ In this report we describe the first use of this method on crude DNA extracts from mouthwash samples and Guthrie cards. These sources of DNA allow non-invasive and retrospective sampling, respectively. A further advantage of ARMS is the avoidance of restriction enzyme cleavage which is subject to problems with incomplete digestion.

The locus detected by the J3.11 probe is closely linked to $C F$ and contains a dimorphism detected by

ICI Pharmaceuticals, Biotechnology Department, Mereside, Alderley Park, Macclesfield, Cheshire SK10 4TG.

C R Newton, S Summers, L E Heptinstall, R S Finniear, D Ogilvie, J C Smith, A F Markham

Nuffield Department of Clinical Medicine, University of Oxford, John Radcliffe Hospital, Oxford OX3 9DU. J R Lynch

Correspondence to Dr Newton.

Received for publication 4 September 1990.

Accepted for publication 3 October 1990. the restriction enzyme MspI ${ }^{3}$ We describe the use of ARMS to determine the J3.11 MspI RFLP genotype of DNA from the sources described above.

\section{Materials and methods}

CHARACTERISATION OF THE J3.11 MspI DIMORPHISM Genomic DNA from a number of healthy volunteers was subjected to PCR amplification using the upstream primer dAAGTTTGAGCATAGGAAAAGTTCTGTGCCC and the downstream primer dCATCCTTGACTCTTCTCTTTCTCAAAGGCC. These primers flank the dimorphic MspI site. Direct sequence analysis was performed with primer dAGTTCTGTGCCCAAAATTGCATCCAAG, which is nested with respect to the upstream amplification primer, using the method previously described. ${ }^{4}$ The sequence characterisation of the $M$ sp I dimorphism is shown in fig 1 . Allele 1 , which lacks the MspI site, and allele 2 are characterised by the sequences CCAG and CCGG respectively at the dimorphic MspI site. During sequencing, a second single base change $A$ to G was noted 23 base pairs upstream of the MspI site. The G variant cosegregated with the MspI site in the samples sequenced. Extensive population studies were not carried out. Appropriate volunteers, who had genotypes 11,12 , and 22 for $\mathrm{J} 3.11$, provided blood, Guthrie spots, and buccal washes for ARMS analysis.

\section{DESIGN OF ARMS PRIMERS}

DNA polymerase isolated from Thermophilus aquaticus (Taq DNA polymerase) will synthesise DNA in a 5' to 3' direction from a primer annealed to a complementary template DNA. Previous studies have shown that alteration of the $3^{\prime}$ terminal nucleotide of a primer, to create a mismatch with the template, is inhibitory to this process. ${ }^{1}$ This inhibition depends on the nature of the nucleotide mismatch. A purinepyrimidine mismatch is less inhibitory than either a purine-purine or pyrimidine-pyrimidine mismatch. Complete inhibition of primer extension has been achieved by introduction of further nucleotide 


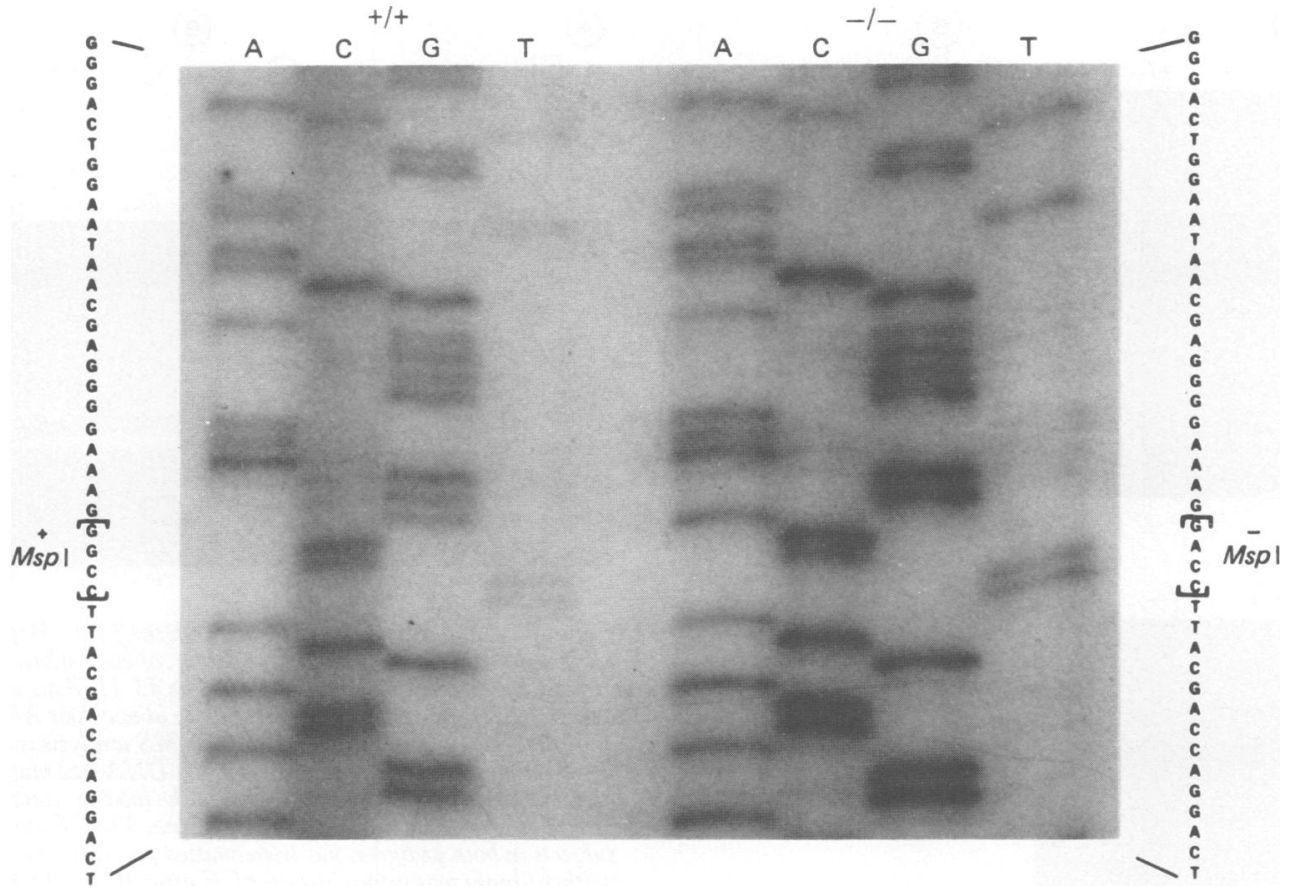

Figure 1 Characterisation of the 73.11 polymorphism by PCR and direct sequencing. The left panel shows the genomic DNA sequence of the MspI+ allele (haplotype 2), the panel on the right shows that of the MspI-allele (haplotype 1).

mismatches near the $3^{\prime}$ terminus of the primer. ${ }^{1}$ For the J3.11 MspI dimorphism the base change $(\mathrm{A} \rightarrow \mathrm{G}$, allele $1 \rightarrow$ allele 2) defined the $3^{\prime} \mathrm{OH}$ terminus of the discriminatory ARMS primers. Because these primers generate either an A-C mismatch or a G-T mismatch we chose to introduce further mismatched base 3 nucleotides from the allele specific $3^{\prime}$ base. The primers were designed with an A-G mismatch at this position. Consequently, the ARMS primers were dTTATATTGTTGTGTCAGGACCAGCATTACA (allele 1) and dTTATATTGTTGTGTCAGGACCAGCATTACG (allele 2). The common primer was the downstream amplification primer described above. Allele specific amplification with each primer pair generated a 550 base pair (approx) product when the appropriate allele was present.

\section{DNA EXTRACTION}

DNA was prepared from buccal epithelial cells according to Lench et al. ${ }^{5}$ However, the cells were also resuspended and washed twice with saline solution. The cells were resuspended in $500 \mu \mathrm{l}$ water, boiled for five minutes, and centrifuged at $12000 \mathrm{~g}$ for five minutes. DNA was extracted from Guthrie cards by the dissection of individual dried blood spots into small fragments. These were boiled in $0.05 \%$ 'Tween 20 ' $(100 \mu \mathrm{l})$. Debris was pelleted by centrifugation at $12000 \mathrm{~g}$ for five minutes.

\section{ARMS ANALYSES}

DNA (10 to $30 \mathrm{ng}$ ) purified from peripheral leucocytes, $10 \mu$ l from supernatants of buccal cell DNA preparations, or $5 \mu \mathrm{l}$ from the supernatants from the Guthrie card DNA isolations, was used directly. All ARMS analyses were performed with concurrent amplification of a $360 \mathrm{bp}$ or $220 \mathrm{bp}$ region of the human $\alpha_{1}$-antitrypsin (AAT) gene $^{4}$ as internal control. The reactions were carried out in pairs using the common primer with the MspI RFLP allele 1 specific primer in one reaction and the $M s p I$ RFLP allele 2 specific primer in the other. All reactions were performed in $100 \mu l$ containing 10 $\mathrm{mmol} / \mathrm{l}$ Tris- $\mathrm{HCl}, \mathrm{pH} 8.3,50 \mathrm{mmol} / \mathrm{l} \mathrm{KCl}, 1.2$ $\mathrm{mmol} / 1 \mathrm{MgCl}_{2}, 0.01 \%$ gelatin, 2 units $\mathrm{Taq}$ polymerase, the four deoxynucleoside triphosphates (100 $\mu \mathrm{mol} / \mathrm{l}$ each), and the appropriate ARMS and internal control primers (1 $\mu \mathrm{mol} / \mathrm{l}$ each). All reactions were overlaid with $50 \mu l$ paraffin oil. The amplification protocol was as follows: denaturation at $92^{\circ} \mathrm{C}$ for two minutes, enzyme addition (at 


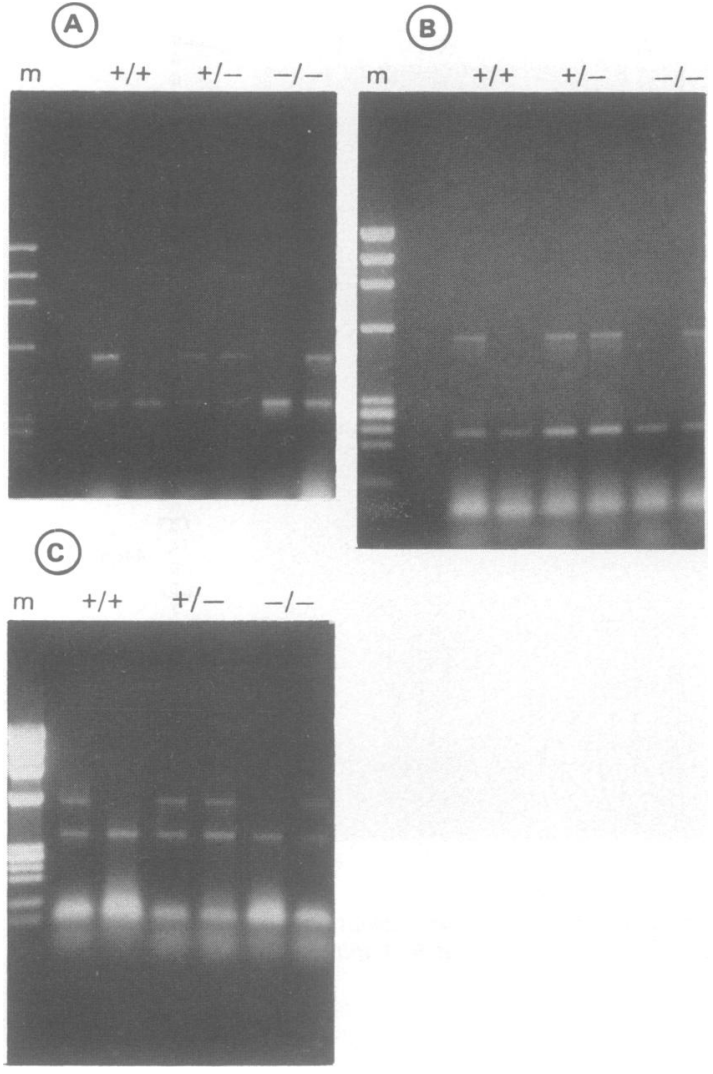

Figure 2 Ethidium bromide stained agarose gel analysis of $A R M S$ reaction products. (A) ARMS analysis of purified genomic DNA. The internal control is a $360 \mathrm{bp}$ fragment of the $A A T$ gene. (B) ARMS analysis of Guthrie card extracts. The internal control is a 220 bp fragment of the AAT gene. $(C)$ $A R M S$ analysis of buccal cell extracts. The internal control is as in $(A)$. m denotes DNA fragment size markers and is an HaeIII digest of bacteriophage $\phi X 174 \mathrm{DNA}(1353,1078,872,603$, $310,281,271,234,118$, and 72 base pairs). + and describe zygosity for the $73.11 \mathrm{MspI}$ dimorphism. In the left of each pair of lanes the allele $2(M s p I+)$ specific $A R M S$ primer was used, in the right of each pair the allele 1 (MspI-) specific primer was used.

$92^{\circ} \mathrm{C}$ ), primer annealing and extension at $60^{\circ} \mathrm{C}$ for four minutes, and denaturation at $92^{\circ} \mathrm{C}$ for two minutes. Forty cycles were performed. The ARMS analyses are shown in figs 2 and 3.

\section{Results}

DEMONSTRATION OF PRIMER SPECIFICITY

The ARMS primers designed as above discriminated between the three test genotypes, defined by direct sequencing, in DNA samples from peripheral leucocytes, Guthrie cards, and buccal epithelial cells (fig 2).

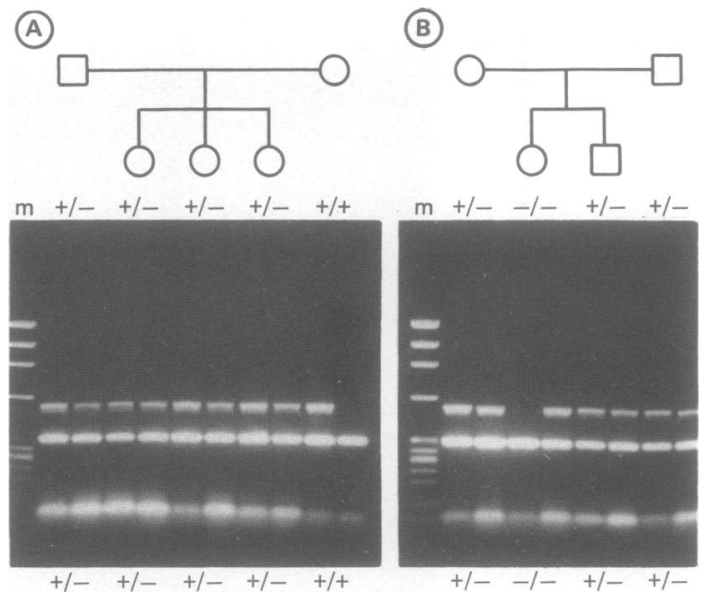

Figure 3 (A) Pedigree of family $A$ with the $73.11 \mathrm{MspI}$ alleles, determined by filter hybridisation, of each subject shown directly below their ARMS analysis. The J3.11 MspI alleles as determined by ARMS are shown directly above their ARMS analysis. (B) As for family $A$. Each $A R M S$ analysis is as described in the legend to fig 2. $m$ denotes DNA size markers, also as described in the legend to fig 2. The internal control is a $360 \mathrm{bp}$ product derived from the AAT gene. The $C F$ status of the subjects in both pedigrees has been omitted for clarity because neither family was informative for CF using the f3.11 MspI $R F L P$.

\section{FAMILY STUDIES}

In order to verify that ARMS is an alternative to the conventional filter hybridisation analysis of the J3.11 MspI RFLP, two CF pedigrees (A and B) were studied (fig 3). These had been previously genotyped for the J3.11 MspI dimorphism as described. ${ }^{3}$ The results from ARMS and filter hybridisation studies were concordant (data not shown).

\section{SECOND SEQUENCE VARIANT}

As noted above, a second sequence variant was observed 23 base pairs upstream of the $G$ to $A$ base change at the dimorphic MspI site. Alternative ARMS primers incorporating this second variant gave identical results to those described above. Thus, a mismatch at this distance from the $3^{\prime}$ terminus of the ARMS primers did not influence the specificity of the reactions.

\section{Discussion}

We have shown that ARMS analysis of DNA can distinguish RFLPs in a rapid and easy manner whether the DNA is isolated pure or as a crude preparation from buccal epithelial cells or from Guthrie cards. This method can be used for early prenatal diagnosis of $\mathrm{CF}$ since analyses can be performed on chorionic villus biopsy and at other CF 
linked polymorphic loci. ${ }^{2}$ Carrier detection can be performed using non-invasive sampling methods and at lower cost than invasive alternatives. ARMS analyses can be performed retrospectively using Guthrie cards; indeed, we have amplified DNA from Guthrie cards 21 years old. ${ }^{6}$ Therefore, retrospective analysis may be carried out when it is required to establish the phase of a linked RFLP in certain families where the key person has died or cannot be traced.

Even though the major CF mutation has been characterised, linkage analysis is still necessary in the majority of CF families. ${ }^{8}$ ARMS analysis will be of value in genotyping of the J3.11. MspI dimorphism until all the CF mutations are characterised.

We wish to thank Dr P Rowlandson for kindly providing the blood samples from the two CF pedigrees used for the family studies.

The ARMS method is the subject of European patent application 0332435 and corresponding world wide patents on behalf of ICI plc.

1 Newton CR, Graham A, Heptinstall LE, et al. Analysis of any point mutation in DNA. The amplification refractory mutation system. Nucleic Acids Res 1989;17:2503-16.

2 Newton CR, Heptinstall LE, Summers C, et al. The amplification refractory mutation system (ARMS) allows prenatal diagnosis and carrier assessment in cystic fibrosis. Lancet 1989;ii:1481-3.

3 Bartels I, Grzeschik KH, Cooper DN, et al. Regional mapping of six cloned DNA sequences on human chromosome 7. Am $\mathrm{f}$ Hum Genet 1986;38:280-7.

4 Newton CR, Kalsheker N, Graham A, et al. Diagnosis of $\alpha 1$ antitrypsin deficiency by enzymatic amplification of human genomic DNA and direct sequencing of polymerase chain reaction products. Nucleic Acids Res 1988;16:8233-43.

5 Lench N, Stanier P, Williamson R. Simple non-invasive method to obtain DNA for gene analysis. Lancet 1988;i:1356-8.

6 Graham A, Newton CR, Powell SJ, et al. Specificity of the polymerase chain reaction in the study of al-antitrypsin deficiency. In: Erlich H, Gibbs R, Kazazian $\mathrm{H}$ Jr, eds. Current communications in molecular biology: polymerase chain reaction. New York: Cold Spring Harbor Laboratory Press, 1989: $105-10$.

7 Riordan JR, Rommens JM, Kerem BS, et al. Identification of the cystic fibrosis gene: cloning and characterization of complementary DNA. Science 1989;245:1066-73.

8 Kerem BS, Rommens JM, Buchanan JA, et al. Identification of the cystic fibrosis gene: genetic analysis. Science 1989;245: 1073-80. 